\title{
Afet Tıbbı Açısından Kimyasal Silah Yaralılarının Yönetimi
}

\author{
İlhan ÖZTÜRK ${ }^{1}$, Ethem GÜNEREN², Alpaslan MAYADAĞLI ${ }^{3}$, Özcan ERDOĞAN ${ }^{4}$
}

\begin{abstract}
Özet
Günümüzde Kimyasal, Biyolojik, Radyolojik ve Nükleer (KBRN) silahlar genellikle terör ve paniğe sebep olmak amacı ile kullanıldıkları gibi kitlesel yok etme veya kapasiteyi bozma amacıyla da kullanılmaktadır. KBRN silahlarının kolay elde edilebilir olması, güçsüz devletlerin elinde kontrolsüz bir güç kaynağı olmasına neden olmuştur. Kimyasal silahların üretimi, depolanması ve kullanımını önleyici uluslararası kararlara, anlaşmalara ve baskılara rağmen, halen kontrolsüz bir şekilde kullanılmasının önüne geçilememektedir. Bazı kimyasalların çift kullanım özelliklerinin olması da ticari izinlerinde ve gümrük geçişlerinde kolaylık sağlamaktadır. Sınır ile gümrüklerden geçişlerde kimyasalların tespitlerinin zorluğu ve erken uyarı sistemlerinin yaygın olmaması tehlikeyi daha da artırmaktadır. İnsanların ve diğer canlıların sağlığını korumaktan sorumlu olan kurum ve kuruluşların konuya önem vermemeleri ise durumu daha da tehlikeli hale getirmektedir.
\end{abstract}

Afet tıbbına göre kimyasal savaş ajanlarıyla yaralanma ve yaralı yönetimi multidisipliner bir yaklaşımı, çalışmayı ve koordinasyonu gerektirmektedir. Özellikle kimyasal silahlarla yaralanma durumunda, yaralıya ilk temas anından itibaren sunulacak olan kurtarma ve sağlı hizmetlerine dair standart uygulamalar ile algoritmalar hususunda akademik çalışmalar ülkemizde ne yazık ki yok denecek kadar sınırlı sayıdadır. Bu belirsizliğin ortadan kaldırılması ve mevcut eksikliğin giderilmesi amacıyla; bilim insanları, adli tıp uzmanları, sağlıkçılar, kimyacılar, mühendisler, arama ve kurtarmacılar, itfaiyeciler, yönetim disiplini mensupları, hukukçular, lojistik uzmanları, güvenlikle ilgili uzmanların ivedilikle ortak çalışmalar yaparak gerekli standart önleme ve müdahale algoritmalarını belirlemeleri gerekmektedir.

Bu çalışmada; örnek bir süreç yönetimi olarak Suriye iç savaşında kimyasal silah olarak kullanılan klor gazı yaralılarının ülkemizdeki tıbbi bakım süreçleri afet tıbbı açısından değerlendirilmiştir.

Anahtar Kelimeler: Afet Tıbbı, KBRN, Kimyasal Silah, Tıbbi Bakım

\footnotetext{
${ }^{1}$ Dr., Afet Koordinatörü, Türk Kızılayı, Ankara

İlgili yazar e-posta/ Corresponding author e-mail: ta2ui.m@gmail.com ORCID No: 0000-0002-8680-5920

2 Prof. Dr., Bezmialem Vakıf Üni., Plastik, Rekonstrüktif ve Estetik Cerrahi ABD, İstanbul

e-posta/e-mail: eguneren@gmail.com ORCID No: 0000-0002-5981-7010

${ }^{3}$ Prof. Dr., Bezmialem Vakıf Üni., Radyasyon Onkolojisi ABD, İstanbul,

e-posta/e-mail: amayadagli@bezmialem.edu.tr ORCID No: 0000-0003-3463-563X

${ }^{4}$ Dr. Öğr. Üyesi, Bezmialem Vakıf Üni., Afet Yönetimi ABD, İstanbul

e-posta/e-mail: oerdogan@bezmialem.edu.tr ORCID No: 0000-0002-4387-6016
}

Bu makaleye atıf yapmak için- To cite this article Öztürk, İ., Güneren, E., Mayadağlı, A. ve Erdoğan, Ö. (2020). Afet Tıbbı Açısından Kimyasal Silah Yaralılarının Yönetimi. Afet ve Risk Dergisi, 3(1), 20 - 30. 


\title{
Management of Chemical Weapons Victims in Terms of Disaster Medicine
}

\begin{abstract}
Today, as Chemical, Biological, Radiological and Nuclear (CBRN) weapons are generally used to cause terror and havoc, they are also used to bring about mass destruction and breach of the capacity. Since CBRN weapons are easily procurable, they became an untrammeled power supply in the hands of weak states. Despite all international judgments, treaties and pressures preventing production, storage and usage of chemical weapons, uncontrolled usage still has not been averted. Dual-use feature of some chemicals provides convenience in their trading permissions and their passing through customs. Because chemical detections are difficult and early warning systems are not prevalent in border crossings and customs entries, there is an increasing danger. Disregard of the agencies and institutions meant to be responsible from protecting human health and health of other species, jeopardizes the situation more.
\end{abstract}

In terms of disaster medicine, management of injuries with chemical warfare agents and injured peoples require a multi-disciplinary approach, study and coordination. Unfortunately, academic studies regarding standard procedures and algorithms of rescue and health services provided to the injured peoples as from the initial contact, - especially in the case of injuries with chemical weapons- have a very limited availability. On the purpose of removing this uncertainty and remedying the current deficiency; scientists, forensic science experts, health care providers, chemists, engineers, search and rescue experts, firefighters, members of the managerial disciplines, legists, logistics specialists and experts related to the security field urgently need to determine required standard algorithms of prevention and response.

In this study; the medical care processes of chlorine gas as chemical weapons wounded in Syria due to Syrian civil war are evaluated in terms of disaster medicine

Keywords: Disaster Medicine, CBRN, Chemical Weapon, Medical Care

\section{GİRİ̧}

Kimyasal, Biyolojik, Radyolojik ve Nükleer (KBRN) silahlar genellikle terör ve paniğe sebep olmak amacı ile kullanıldıkları gibi kitlesel yok etme veya kapasiteyi bozma amacıyla da kullanılırlar. KBRN silahlarının kolay elde edilebilir olması, güçsüz devletlerin elinde kontrolsüz bir güç kaynağı olmasına neden olmuştur (Öztürk, 2011).

Terörizmin tarihçesi çok eskilere kadar uzanır. Değişen dünya ve şartlar doğrultusunda terörizmin metodolojisi ve yöntemleri de değişmiştir. "Küresel Asimetrik Tehdit" șeklinde karşımıza çıkan küresel terör dönemiyle birlikte terör saldırılarının kim tarafından, ne zaman, nerede, nasıl ve kimi hedef alacağı belirsiz bir hale gelmiştir. İletişim ve bilgiye sınırsız şekilde erişim imkânı olan günümüzde teröristlerin işleri hem üretim hem de korunma açısından daha da kolaylaşmıştır. Bundan dolayı günümüzde küresel terörle mücadele için uluslararası ve 
Afet Tıbbı Açısından Kimyasal Silah Yaralılarının Yönetimi

devletlerarası işbirliği kaçınılmaz olmuştur. Bu gerçeğe rağmen uluslararası ilişkilerde devletler, terörü bir koz olarak birbirlerine karşı kullanabilmektedirler (Türköz, 2016).

Suriye'de KS (CW)'ları sivil nüfusa karşı kullanıldığı iddiaları, uluslararası platformda sıklıkla tartışılmıştır. Suriye Hükümet yetkililerince 2012 yılında, uzun süreli kimyasal silah üretim çalışmaları olduğu kabul edilmiştir. Yetkililer, silahlı kuvvetler tarafından saklanan ve güvence altına alınan silahların hiçbir zaman Suriye içinde kullanılmayacağını, ancak dış saldırılara karşı kullanılacağını ifade etmişlerdir. Şubat 2014 tarihli BM İnsan Hakları Konseyi'nce hazırlanan bir raporda, Khan-Al-Assal saldırısında kullanılan kimyasal ajanların, 2013 Ghouta saldırılarında kullanılanlarla aynı özellikleri taşıdığı belirtilmiştir. 2013 yılında Suriye'deki ilk kimyasal saldırıdan sonra diğer saldırılar art arda gerçekleştirilmiştir. Bu saldırılara ait harita Şekil 1'de ve kronolojik süreç Tablo 1'de gösterilmektedir.

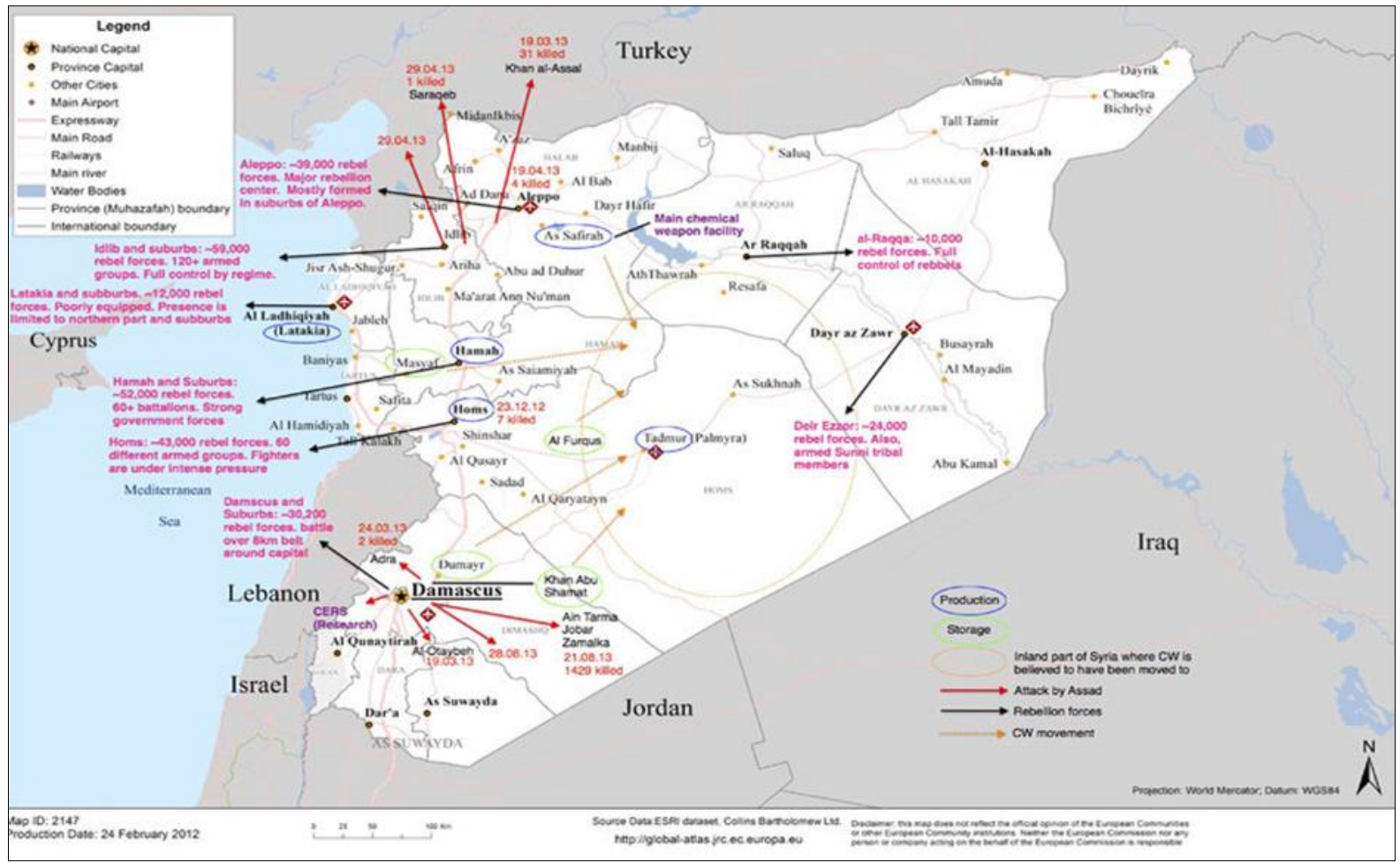

Şekil 1. Suriye’de meydana gelen kimyasal saldırıların yıllara göre dağılımı (Patocka, Jiri, 2016).

Suriye'de başlayan iç savaş esnasında, 23.11.2012 - 07.04.2018 tarihleri arasında Aleppo, Damascus, Damascus banliyöleri, Daraa, Deir Ezzor, Hama, Homs, Idlib, Lattakia ve Raqqa'da düzenlenen kimyasal gaz saldırılarında toplam 1298 kiși hayatını kaybetmiş, binlerce kiși yaralanmıștır. Hayatını kaybedenlerin \% 27,81'i yetişkin kadın, \% 57,01'i yetişkin erkek, \% 6,47'si kız çocuk ve \% 8,70'i ise erkek çocuktur (URL 1).

Bu kimyasal saldırılarda meydana gelen ölümlerin yıllara göre dağılımı Tablo 2'de, yine kimyasal saldırıların meydana geldiği yer ve hayatını kaybedenlerin sayısal dağılımı ise Tablo 3 'te verilmiştir.

Bu yaralılardan bir kısmı sınır kapılarımızdan ülkemize akut ve kronik tıbbi bakım amacıyla getirilmiştir. 
Tablo1. Suriye İç Savaşı'nda meydana gelen kimyasal silah saldırıları (Patocka, Jiri, 2016).

\begin{tabular}{|c|c|c|c|c|c|}
\hline Saldırı Tarihi & Konum & $\begin{array}{l}\text { Kim } \\
\text { Tarafından } \\
\text { Yapıldığı }\end{array}$ & $\begin{array}{l}\text { Sivil } \\
\text { Kurbanlar } \\
\text { Ölü/Yaralı }\end{array}$ & $\begin{array}{l}\text { Asker Kurbanlar } \\
\text { Ölü/Yaralı }\end{array}$ & $\begin{array}{l}\text { Kimyasal } \\
\text { Ajan }\end{array}$ \\
\hline 17 Ekim 2012 & Salgin & & & & \\
\hline 23 Aralık 2012 & Al-Bayadah & $\begin{array}{l}\text { Suriye } \\
\text { Askerleri }\end{array}$ & $0 / 5$ & 0/Approx. 100 & $\begin{array}{l}\text { Ajan } \\
15^{* * *}\end{array}$ \\
\hline 13, 14 Mart 2013 & $\begin{array}{l}\text { Daraya and } \\
\text { Otaybah }\end{array}$ & & & & \\
\hline 19 Mart 2013 & Khan al-Asal & $\begin{array}{l}\text { Suriye } \\
\text { Askerleri }\end{array}$ & $19 / 107$ & $1 / 17$ & Sarin \\
\hline 24 Mart 2013 & Adra & & & & \\
\hline $\begin{array}{l}11,12 \text { Nisan } \\
2013\end{array}$ & Jobar & & & & \\
\hline 13 Nisan 2013 & $\begin{array}{l}\text { Sheikh Maqsood, } \\
\text { Jobar }\end{array}$ & Kürt Güçleri & $3 />12$ & & \\
\hline 14 Nisan 2013 & Jobar & & & & \\
\hline 29 Nisan 2013 & Saraqib & $\begin{array}{l}\text { Suriye } \\
\text { Askerleri }\end{array}$ & $1 / 10$ & 2 yaralı & Sarin \\
\hline $\begin{array}{l}23 \text { Mayıs, } \\
5 \text { Ağustos } 2013\end{array}$ & Adra & & & & \\
\hline 21 Ağustos 2013 & Ghouta & & $\begin{array}{l}734 \text { ölü, yaralı } \\
\text { sayısı } \\
\text { bilinmiyor }\end{array}$ & & Sarin \\
\hline 21 Ağustos 2013 & $\begin{array}{l}\text { Muadamiyat al- } \\
\text { Sham }\end{array}$ & & $\begin{array}{l}103 \text { ölü, yaralı } \\
\text { sayısı } \\
\text { bilinmiyor }\end{array}$ & & Sarin \\
\hline 22 Ağustos 2013 & Jobar & $\begin{array}{l}\text { Suriye } \\
\text { Askerleri }\end{array}$ & & 16 yaralı & \\
\hline 24 Ağustos 2013 & Jobar & $\begin{array}{l}\text { Suriye } \\
\text { Askerleri }\end{array}$ & & 24 yaralı & Sarin \\
\hline 25 Ağustos 2013 & Ashrafiyat & $\begin{array}{l}\text { Suriye } \\
\text { Askerleri }\end{array}$ & & 5 yaralı & Sarin \\
\hline $\begin{array}{l}10,11,12 \text { Nisan } \\
2014\end{array}$ & Kafr Zita & $\begin{array}{l}\text { Suriye } \\
\text { Karşıtları }\end{array}$ & $2 / 112$ & & Chlorine \\
\hline $\begin{array}{l}12,13 \text { Nisan } \\
2014\end{array}$ & Al-Tamanah & $\begin{array}{l}\text { Suriye } \\
\text { Karşıtları }\end{array}$ & $0 / 137$ & & \\
\hline 14 Nisan 2014 & Halfaya & & $0 / 4$ & & Chlorine \\
\hline 16 Nisan 2014 & Kafr Zita & $\begin{array}{l}\text { Suriye } \\
\text { Karşıtları }\end{array}$ & $0 / 4$ & & Chlorine \\
\hline 18 Nisan 2014 & $\begin{array}{l}\text { Al-Tamanah } \\
\text { Kafr Zita }\end{array}$ & $\begin{array}{l}\text { Suriye } \\
\text { Karşıtları }\end{array}$ & $\begin{array}{l}4 / 70 \\
0 / 100\end{array}$ & & Chlorine \\
\hline 21 Nisan 2014 & Talmenes * & $\begin{array}{l}\text { Suriye } \\
\text { Karşıtları }\end{array}$ & $3 / 133$ & & Chlorine \\
\hline 29 Nisan 2014 & Al-Tamanah & $\begin{array}{l}\text { Suriye } \\
\text { Karşıtları }\end{array}$ & $0 / 35$ & & Chlorine \\
\hline 19 Mayıs 2014 & Kafr Zita & $\begin{array}{l}\text { Suriye } \\
\text { Karşıtları }\end{array}$ & $1 / 130$ & & Chlorine \\
\hline 21 Mayıs 2014 & Kafr Zita & $\begin{array}{l}\text { Suriye } \\
\text { Karşıtları }\end{array}$ & $0 / 4$ & & Chlorine \\
\hline 22 Mayıs 2014 & Al-Tamanah & $\begin{array}{l}\text { Suriye } \\
\text { Karşıtları }\end{array}$ & $4 / 12$ & & Chlorine \\
\hline
\end{tabular}


Afet Tıbbı Açısından Kimyasal Silah Yaralılarının Yönetimi

\begin{tabular}{|c|c|c|c|c|c|}
\hline 22 Mayıs 2014 & Kafr Zita & $\begin{array}{l}\text { Suriye } \\
\text { Karsitları }\end{array}$ & $12 / 38$ & & Chlorine \\
\hline 29 Mayıs 2014 & Al-Lataminah & & $0 / 17$ & & Chlorine \\
\hline $\begin{array}{l}12 \text { Temmuz } \\
2014\end{array}$ & Avdiko & Kürt Güçleri & $0 / 3$ & & $\begin{array}{l}\text { Mustard } \\
\text { gas }\end{array}$ \\
\hline $\begin{array}{l}27 \text { Temmuz } \\
2014\end{array}$ & Kafr Zita & $\begin{array}{l}\text { Suriye } \\
\text { Karşitları }\end{array}$ & & & Chlorine \\
\hline $\begin{array}{l}28,30 \text { Ağustos } \\
2014\end{array}$ & Kafr Zita & $\begin{array}{l}\text { Suriye } \\
\text { Karșitları }\end{array}$ & & & Chlorine \\
\hline 16 Mart 2015 & Qmenas Sarmin & $\mathrm{AaS}$ and $\mathrm{JaA}^{* *}$ & $\begin{array}{l}0 / 70 \\
6 / 30\end{array}$ & & Chlorine \\
\hline 23 Mart 2015 & Binnish & $\begin{array}{l}\text { Suriye } \\
\text { Karşitları }\end{array}$ & $30 / 0$ & & Chlorine \\
\hline 24 Mart 2015 & Binnish & & $0 / 30$ & & Chlorine \\
\hline 28 Haziran 2015 & Tell Brak & Kürt Güçleri & & $0 / 12$ & $\begin{array}{l}\text { Mustard } \\
\text { gas }\end{array}$ \\
\hline 21 Ağustos 2015 & Mare & İslami Cephe & $0 / 30$ & & $\begin{array}{l}\text { Mustard } \\
\text { gas }\end{array}$ \\
\hline
\end{tabular}

Tablo 2. Suriye'de yapılan kimyasal saldırılarda meydana gelen ölümlerin yıllara göre dağılımı (URL 1)

\begin{tabular}{|c|c|c|}
\hline Sıra No. & $\begin{array}{c}\text { Kimyasal Saldırının Meydana } \\
\text { Geldiği Yıl }\end{array}$ & $\begin{array}{c}\text { Hayatını Kaybedenlerin } \\
\text { Sayısı }\end{array}$ \\
\hline $\mathbf{1}$ & 2012 & 8 \\
\hline $\mathbf{2}$ & 2013 & 997 \\
\hline $\mathbf{3}$ & 2014 & 43 \\
\hline $\mathbf{4}$ & 2015 & 17 \\
\hline $\mathbf{5}$ & 2016 & 49 \\
\hline $\mathbf{6}$ & 2017 & 90 \\
\hline $\mathbf{7}$ & 2018 & 87 \\
\hline $\mathbf{8}$ & Yll Kayıtlı Olmayan & 7 \\
\hline & Toplam & $\mathbf{1 2 9 8}$ \\
\hline
\end{tabular}

Tablo 3. Suriye'de yapılan kimyasal saldırıların meydana geldiği yer ve hayatını kaybedenlerin sayısal dağılımı (URL 1)

\begin{tabular}{|c|c|c|}
\hline Sıra No. & $\begin{array}{c}\text { Kimyasal Saldırının Meydana } \\
\text { Geldiği Yer }\end{array}$ & $\begin{array}{c}\text { Hayatını Kaybedenlerin } \\
\text { Sayısı }\end{array}$ \\
\hline $\mathbf{1}$ & Aleppo & 49 \\
\hline $\mathbf{2}$ & Damascus & 87 \\
\hline $\mathbf{3}$ & Damascus'un Banliyöleri & 975 \\
\hline $\mathbf{4}$ & Daraa & 12 \\
\hline $\mathbf{5}$ & Deir Ezzor & 10 \\
\hline $\mathbf{6}$ & Hama & 69 \\
\hline $\mathbf{7}$ & Homs & 14 \\
\hline
\end{tabular}




\begin{tabular}{|c|c|c|}
\hline $\mathbf{8}$ & Idlib & 78 \\
\hline $\mathbf{9}$ & Lattakia & 2 \\
\hline $\mathbf{1 0}$ & Raqqa & 1 \\
\hline $\mathbf{1 1}$ & Diğer Bölgeler & 1 \\
\hline & Toplam & $\mathbf{1 2 9 8}$ \\
\hline
\end{tabular}

\section{GEREÇ ve YÖNTEM}

$\mathrm{Bu}$ araştırma; retrospektif ve kesitsel olarak Hatay iline getirilen klor gazına maruz kalmış vakalar üzerinde yapılmıștır.

\section{BULGULAR}

\subsection{04.2014 ve 21.04.2014 Tarihlerinde Reyhanlı Cilvegözü Sınır Kapısından Getirilen Kimyasal Saldırı Yaralıları}

Vakalarda kimyasal saldırı maruziyeti belirtileri bulunması nedeniyle; öncelikle Afet ve Acil Durum Yönetimi Başkanlığı (AFAD) tarafından tespit ve arındırma işlemleri Cilvegözü sınır kapısı bölgesinde yapıldıktan sonra Reyhanlı Devlet Hastanesi Acil Servisinde tetkik ve ilk tedavileri gerçekleştirilmiştir.

Hastaların kan ve idrar numuneleri alınarak Reyhanlı Devlet Hastanesinde ve Antakya Devlet Hastanesinde muhafaza edilmiștir. Reyhanlı Devlet Hastanesine başvuran hastaların ileri tedavileri yapılmak üzere Mustafa Kemal Üniversitesi Sağlık Uygulama ve Araştırma Hastanesine sevkleri yapılmış ve acil yardım ambulansları tarafından nakilleri sağlanmıștır. Bu vakalardan ikisine ait BT görüntüleri Şekil 2'de görülmektedir. Yine bu vakalara ait bazı klinik bilgiler Tablo 4 'te verilmektedir.
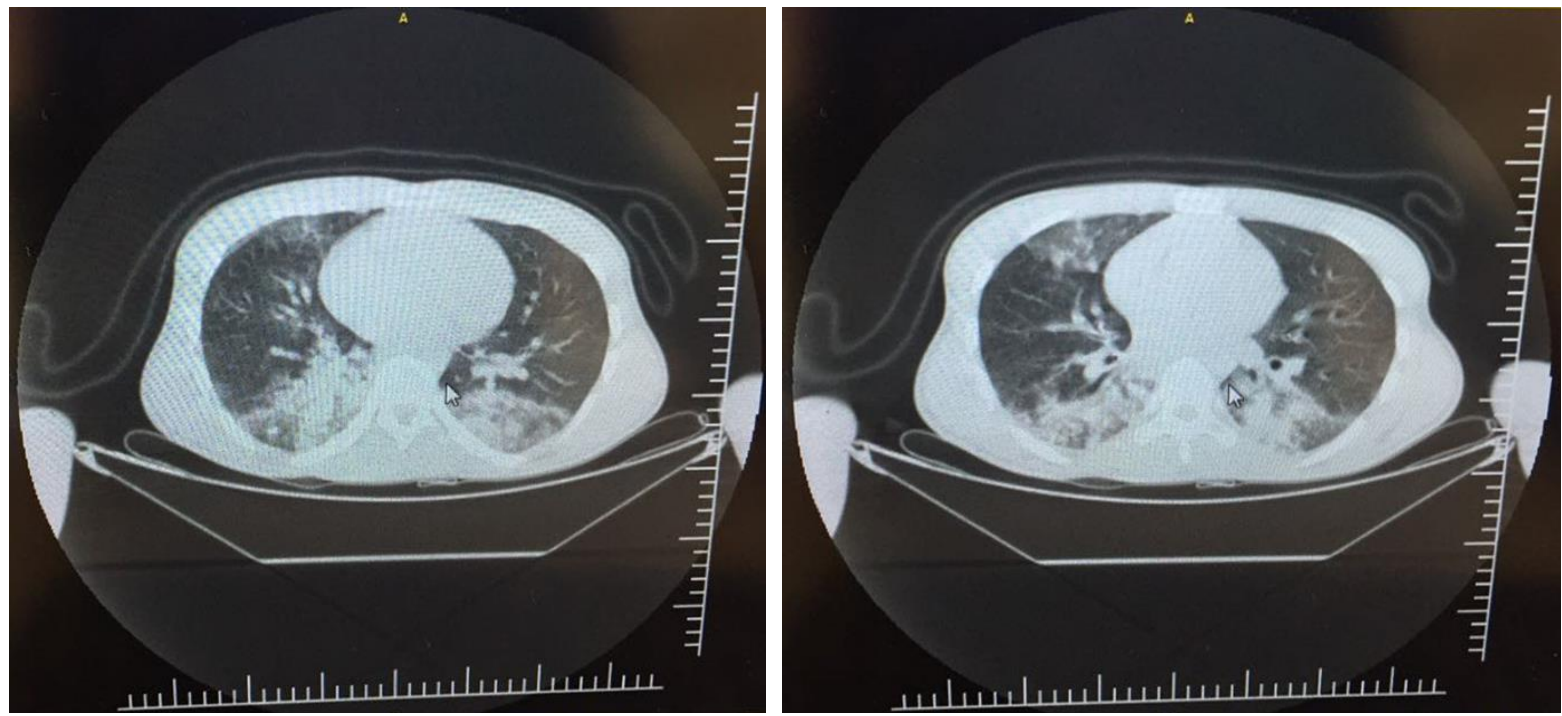

Şekil 2. Vakalara ait BT görüntüleri (Hatay İl Sağlık Müdürlüğü, 2014). 
Tablo 4. 12.04.2014 ve 21.04.2014 tarihlerinde Hatay İli Reyhanlı İlçesi Cilvegözü sınır kapısından getirilen kimyasal yaralılara ilişkin bazı bilgiler (Hatay İl Sağlık Müdürlüğü, 2014)

\begin{tabular}{|c|c|c|c|c|c|c|c|c|c|c|}
\hline$\frac{\sqrt{3}}{\frac{\pi}{7}}$ & $\begin{array}{l}\stackrel{+}{+} \\
\stackrel{0}{0} \\
\stackrel{+}{0} \\
\stackrel{N}{N}\end{array}$ & $\stackrel{+}{\sim}$ & 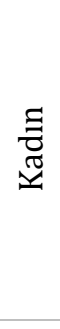 & 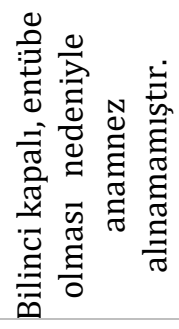 & 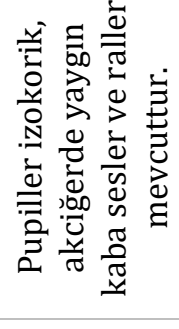 & 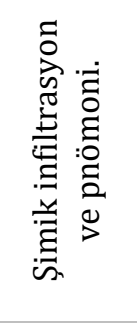 & ' & ' & ' & ' \\
\hline 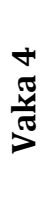 & 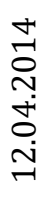 & $\widehat{N}$ & 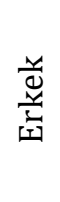 & 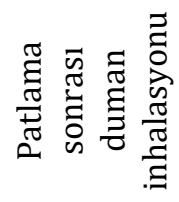 & ' & ' & 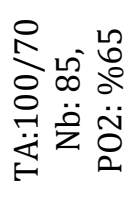 & $\stackrel{\text { 늑 }}{\longrightarrow}$ & + & 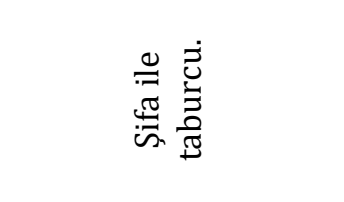 \\
\hline $\begin{array}{l}n \\
\frac{\pi}{\pi} \\
\frac{\pi}{7}\end{array}$ & 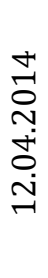 & $\stackrel{\llcorner}{N}$ & 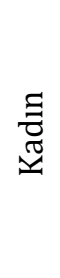 & 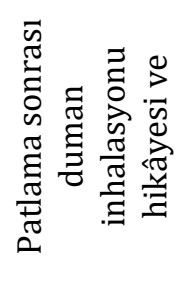 & 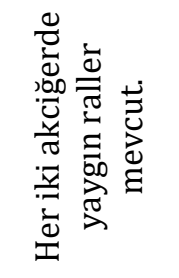 & 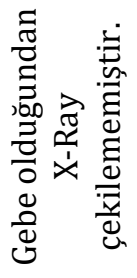 & 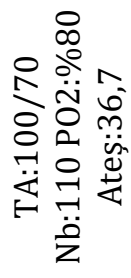 & $\stackrel{2}{\longrightarrow}$ & $m$ & 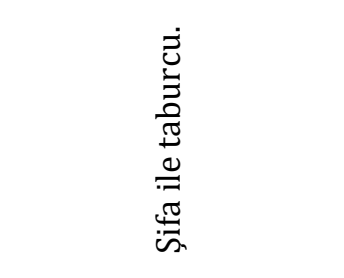 \\
\hline 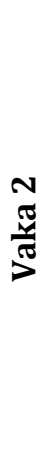 & 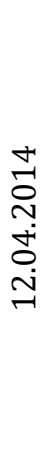 & மे & $\begin{array}{l}\Xi \\
\tilde{\sigma} \\
\tilde{\Xi}\end{array}$ & 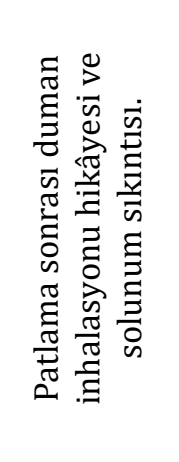 & 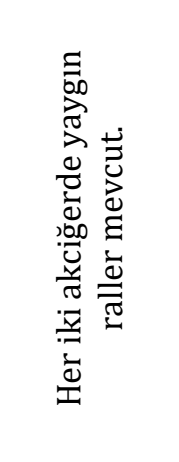 & 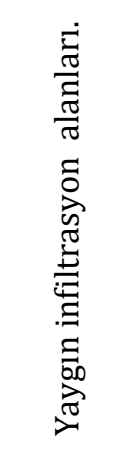 & 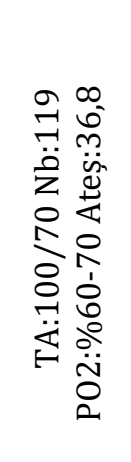 & $\stackrel{2 \Omega}{\longrightarrow}$ & ' & 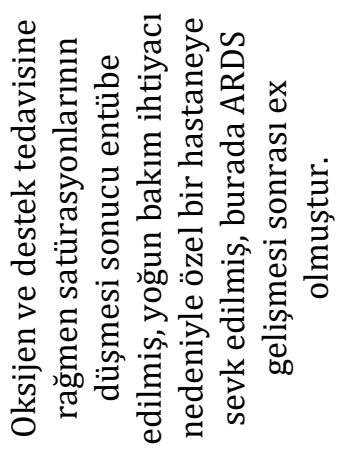 \\
\hline$\frac{7}{\sqrt[7]{7}}$ & 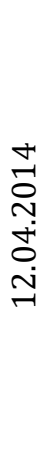 & $\stackrel{\bullet}{m}$ & $\Xi$ & 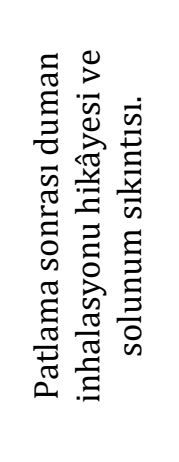 & 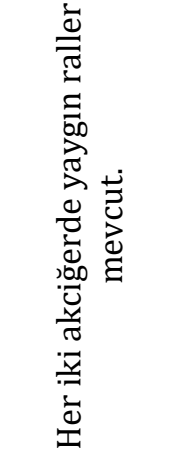 & 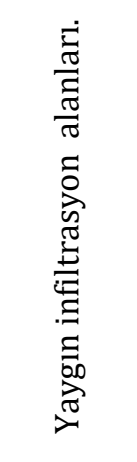 & 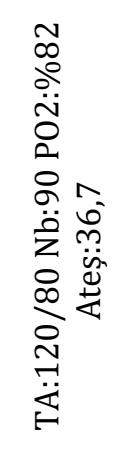 & $\stackrel{2}{\sim}$ & $m$ & 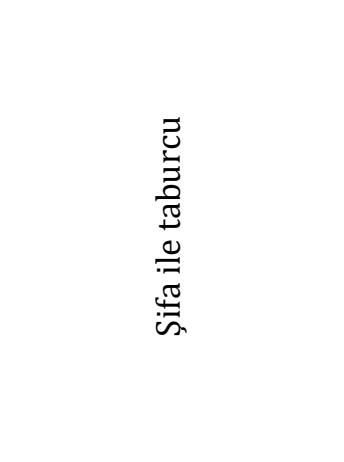 \\
\hline & 㿣 & స్ర & $\stackrel{0}{0}$ & 默 & 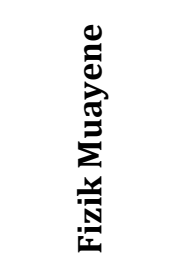 & 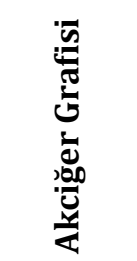 & 泀 & $\frac{\mathscr{V}}{\mathfrak{v}}$ & ט: & 岕 \\
\hline
\end{tabular}




\subsection{04.2017 Tarihinde Reyhanlı Cilvegözü Sınır Kapısından Getirilen Kimyasal Saldırı Yaralıları}

04/04/2017 tarihinde saat 11:05 civarında Reyhanlı Cilvegözü Sınır Kapısı'na getirilen hastalarda kimyasal saldırı bulguları olduğundan; şüpheli temaslıların kontrolleri öncelikle Afet ve Acil Durum Yönetimi Başkanlığı (AFAD) tarafından yapılmış, sahada arındırma işleminin ardından hastaneye nakilleri sağlanmıştır.

Bahse konu 18 vakanın 13'ü trakrium, atropin ve dormikum ile entübe edilmiş (\%72.22) şekilde Cilvegözü sınır kapısına getirilmiş, sınır bölgesinde uzmanlarca arındırma işlemi yapılarak Hatay Devlet Hastanesine ambulanslarla nakledilmiş, hastanenin arındırma ünitesinde arındırma işlemi uygulandıktan sonra acil ünitesine alınmışlardır.

Getirilen vakalardan 9'unun erkek, 9'unun kadın olduğu belirlenmiștir. Erkek ve kadınların her iki grubun da yașları 13 ile 40 arasındadır (ortalaması 21.55).

Vakaların tamamına "X49: Kimyasallar ve diğer ve tanımlanmamış zararlı maddelere maruz kalma" ICD 10 tanı kodu verilmiștir. Bu vakalara ilișkin bazı klinik bilgiler Tablo 5'te görülmektedir.

Acil ünitesinde Anexate $0,5 \mathrm{mg} / 5 \mathrm{ml}$ ampul verilen hastaların 15-20 dakika sonra spontan solunumlarının başladığı ve tamamının bilinçlerinin açıldığı tespit edilmiştir. Hastalar ekstübe edilerek servise takip amaçlı çıkartılmıştır. Vakaların tamamına damar yolu açılıp oksijen destek tedavisi verilmeye başlanmış, \%0.9 NaCl $100 \mathrm{cc}$ /saat hızında başlanmış, ilk 1000 cc'sinin içine 6 ampul N-Asetil Sistein ve prednizolon $100 \mathrm{mg}$ ampul infuzyon şeklinde verilmiştir.

Tablo 5. 04.04.2017 Tarihinde Reyhanlı Cilvegözü Sınır Kapısından Getirilen Kimyasal Yaralılara ilişkin bazı bilgiler (Hatay İl Sağlık Müdürlüğü Acil Sağlık Hizmetleri Başkanlığı, 2017)

\begin{tabular}{|c|c|c|c|c|c|c|}
\hline & Cinsiyet & Yaş & Entübe & $\begin{array}{l}\text { Ral ve } \\
\text { Ronküs }\end{array}$ & $\begin{array}{c}\text { Akciğer BT'sinde } \\
\text { Buzlu Cam Görünümü }\end{array}$ & $\begin{array}{c}\text { Periferik Kanda } \mathrm{Na}^{+} \\
\text {Seviyesinin Alt } \\
\text { Sinırına Düşmesi }\end{array}$ \\
\hline Vaka 1 & $\mathbf{K}$ & 40 & Evet & Evet & Hayır & Hayır \\
\hline Vaka 2 & $\mathbf{K}$ & 40 & Evet & Evet & - & Evet \\
\hline Vaka 3 & $\mathbf{K}$ & 33 & Evet & Evet & - & Evet \\
\hline Vaka 4 & $\mathbf{E}$ & 13 & Hayır & Evet & - & Evet \\
\hline Vaka 5 & $\mathbf{K}$ & 14 & Evet & Evet & Hayır & Evet \\
\hline Vaka 6 & $\mathbf{K}$ & 40 & Evet & Evet & Hayır & Evet \\
\hline Vaka 7 & E & 33 & Hayır & Evet & Hayır & Evet \\
\hline Vaka 8 & E & 14 & Evet & Evet & Evet & Evet \\
\hline Vaka 9 & $\mathbf{K}$ & 25 & Evet & Evet & Hayır & Evet \\
\hline Vaka 10 & $\mathbf{E}$ & 13 & Evet & Evet & Evet & Evet \\
\hline Vaka 11 & $\mathbf{E}$ & 25 & Evet & Evet & Evet & Evet \\
\hline Vaka 12 & E & 17 & Evet & Evet & Hayır & Hayır \\
\hline Vaka 13 & $\mathbf{E}$ & 17 & Hayır & Evet & Hayır & Evet \\
\hline Vaka 14 & $\mathbf{E}$ & 22 & Hayır & Evet & Hayır & Evet \\
\hline Vaka 15 & $\mathbf{K}$ & 13 & Evet & Evet & Hayır & Evet \\
\hline Vaka 16 & $\mathbf{E}$ & 40 & Evet & Evet & Hayır & Evet \\
\hline Vaka 16 & $\mathbf{E}$ & 40 & Evet & Evet & Hayır & Evet \\
\hline Vaka 17 & $\mathbf{K}$ & 35 & Hayır & Evet & Hayır & Evet \\
\hline Vaka 18 & $\mathbf{K}$ & 22 & Evet & Evet & Hayır & Hayır \\
\hline
\end{tabular}


18 vakanın 13 tanesi entübe şekilde hastaneye getirilmiştir. Yine vakaların tamamının fizik muayenelerinde her iki akciğerde dinlemekle yaygın şekilde ral ve ronküs mevcudiyeti dikkat çekmektedir.

18 vakanın tamamına radyo opak madde kullanılmadan akciğer tomografisi çekilmiş ve 5'inin akciğerinde bilateral buzlu cam görünümü ve konsolidasyon alanları görülmüștür (\%27.7). Bir vakanın ise sağ akciğer orta lobunda mozaik atenüasyon paterni gözlenmiștir (\%5.55). Bu vakalardan ikisine ait BT görüntüleri Şekil 3'te görülmektedir.
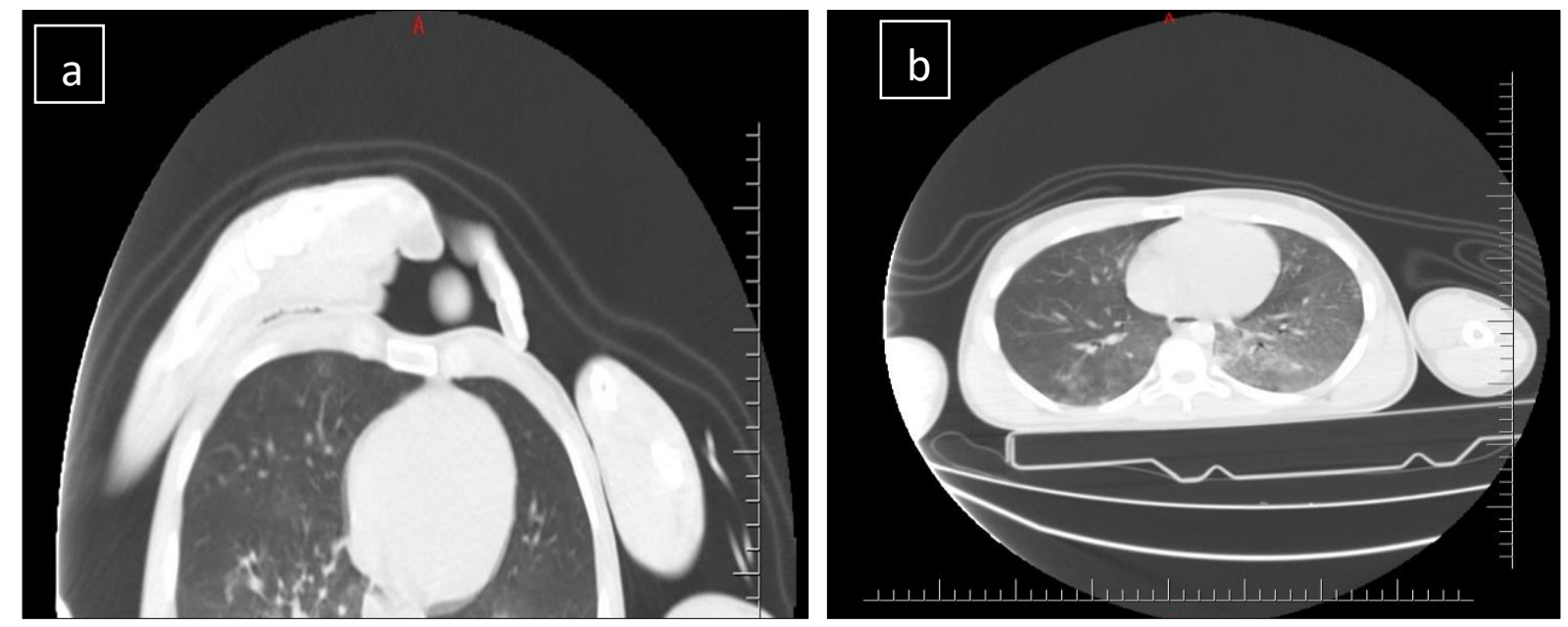

Şekil 3. Vakalara ait BT görüntüleri a) 25 yaşında erkek hasta, her iki akciğer buzlu cam manzarası ve konsolide alanlar (Hatay İl Sağlık Müdürlüğü Acil Sağlık Hizmetleri Başkanlığı, 2017), b) 14 yașında erkek hasta, akciğer bilateral üst loblarda ve sağ akciğer alt lobda multiple buzlu cam görünümü (Hatay İl Sağlı Müdürlüğü Acil Sağlık Hizmetleri Başkanlı̆̆ı, 2017).

Laboratuar tetkiklerinde ise; birinci ve ikinci gün yapılan biyokimya analizlerinde, 18 vakanın 15 'inde (\%83.33) $\mathrm{Na}+$ değerlerinin normalin alt sınırlarında (136-140 mmol/L) olduğu dikkati çekmiştir.

Vakaların tamamı 48 saat içerisinde şifa ile taburcu olmuşlardır.

\section{TARTIŞMA}

Klor gazı göz ve cilt irritasyonu, solunum yolu irritasyonu, solunum sıkıntısı ve öksürük, boğaz ağrısı ve gögüste sıkışma hissi oluşturur. İnsana etkili olan havadaki ölçülebilir konsantrasyonu 2 $\mathrm{mg} / \mathrm{m} 3$, insanların tolere edemediği havadaki ölçülebilir konsantrasyonu $25 \mathrm{mg} / \mathrm{m} 3$ 'tür. Araştırmaya dahil edilen toplam 23 vakanın tamamının $25 \mathrm{mg} / \mathrm{m} 3$ 'ten daha yoğun klor gazına maruz kaldıkları klinik bulgu ve görüntüleme analizlerinden anlaşılmaktadır.

İkinci Dünya Savaşında kullanılan klor gazının etkilerinin incelendiği kohort araştırmasına göre; klor gazına kısa süreli maruz kalan 685 vakanın araştırıldığı saha gözlem araştırmasında mortalite oranı \%5'in üzerinde olduğu, hayatta kalanlarda ise bronşit semptomlarının bulunduğu belirtilmiştir. Aynı araştırmanın maruziyetten sonra 4 ay süre geçen 562 kişiden oluşan bir gruptaki fizik muayene kayıtları araştırmasına göre; araştırma grubunun \%30'unda bronşit ve $\% 22$ 'sinde amfizem geliștiği belirlenmiștir. Yine aynı araștırmanın maruziyetten sonra 10 yıl süre geçen 96 kişiden oluşan bir gruptaki fizik muayene kayıtları ve göğüs röntgenleri üzerinde yapılan bir araştırmaya göre; araștırma grubunun \%10'unda kesinlikle klora bağlı, \%7'sinde muhtemelen klora bağlı bronşit ve/veya amfizem olduğu, \%83'ünde ise klora bağlı herhangi bir sağlık problemi olmadığı belirlenmiştir (Das R, 1993). 
12.04.2014 ve 21.04.2014 tarihlerinde Reyhanlı Cilvegözü sınır kapısından getirilen kimyasal saldırı vakalarında her iki akciğerde dinlemekle kaba ral ve ronküsler (\%80), solunum sıkıntısı (\%100) ve akciğerlerinde yaygın infiltrasyon alanları (\%60) tespit edilmiștir. Vakalardan biri oksijen ve destek tedavisine rağmen satürasyonlarının düşmesi sonucu entübe edilmiş, yoğun bakım ünitesinde Akut Respiratuar Distres Sendromu (ARDS) gelișmesi sonrası ex olmuştur (\%20). İkinci Dünya Savaşındaki mortalite oranıyla aradaki farkın \%15 gibi bariz bir şekilde fazla olmasının nedenleri; maruz kalınan gazın yoğunluğu, Suriye sınırları içerisinde acil müdahale ve solunum destek imkanlarının kısıtlı ve yetersiz seviyede olması, tıbbi bakımda gecikme olması sayılabilir.

04.04.2017 tarihinde Reyhanlı Cilvegözü sınır kapısından getirilen kimyasal saldırı vakalarında solunum sıkıntısı nedeniyle entübe (\%72.22), her iki akciğerde dinlemekle kaba ral ve ronküsler (\%100), akciğer bilgisayarlı tomografi (BT)'lerinde buzlu cam görünümü (\%16.66) ve periferik kanda sodyum $(\mathrm{Na}+)$ değerinin normal seviyesinin alt sınırına düștüğü (\%83.33) tespit edilmiștir. Bunun nedeni; hücre dışı ortamdaki anyon ve katyon dengesinin bozulması olarak değerlendirilmiştir. Bu vakaların tamamı oksijen desteği verilerek şifa ile taburcu olmuşlardır.

\section{SONUÇLAR}

Kimyasal silah maruziyeti olan tüm vakaların tıbbi bakım süreçleri uzmanlık, büyük önem ve dikkat gerektiren bir süreçtir. Başta doktorlar olmak üzere tüm sağllk personeli ve sahada aktif görev alan herkesin; kimyasal silahların sağlığa olan etkileri, korunma yolları, antidotlar, kişisel arındırma ve yaralı arındırma yöntemleri, sağlık olay yeri ve hastane yönetimi, ajanın çeşidine göre sahada ve hastanede tıbbi bakım süreçleri hususlarında eğitilmesi ve düzenli olarak tatbikatlar düzenlenmesi büyük önem taşımaktadır.

Klor gazı teması olan vakalarda klinik bakım esnasında solunum fonksiyonları düzenli olarak takip edilmeli, solunum fonksiyon testleri ihmal edilmemeli, tespit edilen fonksiyon eksikliği gecikmeksizin desteklenmeli ve tedavi edilmelidir

Kitle imha silahı temaslısı bir vaka geldiğinde HAP KBRN prosedürleri gereği vaka acile alınmadan önce kimyasal kalıntı olup olmadığı tespit edilmeli, arındırma yeterliliği kontrol edilmelidir. Kimyasal tespit edilirse arındırma yapılmadan acil ünitesine vaka kabulü yapılmamalıdır.

Arındırma ünitesi; acile yakın ancak hareketli, ayaktan ve sedye ile getirilen yaralıların aynı anda birbirlerini engellemeyecek şekilde tesis edilmelidir. Kitlesel yaralanma durumunda, ayaktan ve sedye ile gelecek yaralıların arındırma süreleri göz önüne alındığında can kaybının artacağı kaçınılmaz bir sonuç olacaktır. Kitlesel arındırma ihtiyacına karşıllı gerekli altyapı referans hastanelerde tesis edilmelidir. Kitlesel arındırma amacıyla, hastane aciline uygun mesafede, kurbanların toplu olarak arındırılabileceği açık alan arındırma sistemleri tesis edilmelidir.

\section{KAYNAKLAR}

Das R, B. P. (1993, Mayıs-Haziran). Clorin Gas Exposure and The Lung: A Review. Texicology and Industrial Health, 3(9), 439-455. doi:10.1177/074823379300900304

Hatay İl Sağlık Müdürlüğü. (2014). HataKamu Hastaneleri Kurumu Başkanlığı Hastane Bilgi Sistemleri Veri Tabanı. Hatay, Cilvegözü. 
Afet Tıbbı Açısından Kimyasal Silah Yaralılarının Yönetimi

Hatay İl Sağlık Müdürlüğü. (2014). Kamu Hastaneleri Kurumu Hatay Devlet Hastanesi Hastane Bilgi Sistemi. Hatay, Reyhanl..

Hatay İl Sağlık Müdürlüğü Acil Sağlık Hizmetleri Başkanlığı. (2017). Acil Sağlık Hizmetleri Bilgi Sistemi. Hatay, Cilvegözü.

Öztürk, D. İ. (2011). Kimyasal Silahlar ve Tedavi Rehberi (1. Baskı b.). Ankara: Poyraz Ofset Büyük San. Cd. No: 99/88.

Patocka, Jiri. (2016, Mart). Syria Conflict and Chemical Weapons: What is The Reality? Mil. Med. Sci. Lett. (Voj. Zdrav. Listy)(85), 1-5. doi:10.31482/mmsl.2016.006

Türköz, Ş. (2016, Nisan). Küresel Terörizm Sorununa Güvenlik Persfektifli Bir Yaklaşım. Niğde Üniversitesi Íktisadi ve İdari Bilimler Fakültesi Dergisi, 2(9), 153-162.

URL 1, The Violation Documentation Center in Syria. The Violation Documentation Center in Syria (2018, 04 07), https://vdc-sy.net/en/ Son erişim tarihi: 26.11.2019) 